\title{
Using Thromboelastography to Predict Blood Loss After Off-Pump Coronary Artery Bypass Grafting
}

This article was published in the following Dove Press journal: International Journal of General Medicine

\author{
Yu Liu' \\ Wen-Li Zhang' \\ Ji-Qiang $\mathrm{Bu}^{\prime}$ \\ Jian-Jun $\mathrm{Gu}^{\prime}$ \\ Yong-Quan Sun' \\ Hong-Zhan Cui' \\ Da-Wei Wang ${ }^{2}$ \\ Zi-Ying Chen'
}

'Department of Cardiac Surgery, Second Hospital of Hebei Medical University, Shi Jiazhuang, 050000, People's Republic of China; ${ }^{2}$ Department of Cardiac Surgery, The First Affiliated Hospital of Hebei North University, Zhangjiakou, 075000, People's Republic of China
Correspondence: Zi-Ying Chen

Department of Cardiac Surgery, Second Hospital of Hebei Medical University, No. 215 of Heping West Road, XinHua

District, Shijiazhuang, 050000, People's

Republic of China

Tel +86 I5803210520

Fax +8631166002995

Email chenziying258@163.com
Objective: This study aims to investigate the value of thromboelastography (TEG) in predicting blood loss, and its relationship with blood transfusion demand, during the perioperative period in off-pump coronary artery bypass grafting (OPCABG).

Methods: The data of 398 patients undergoing OPCABG were retrospectively analyzed. Blood was drawn before anesthesia induction (T1) and at 10 minutes after heparin neutralization (T2) for further TEG detection. The patients were divided into two groups based on the results at T2: a TEG normal group and a TEG abnormal group. Logistic regression analysis was used to predict the related factors contributing to the significant increase in perioperative blood loss (more than $20 \%$ of the estimated blood volume).

Results: There were 277 (69.6\%) patients in the TEG normal group and 121 (30.4\%) in the TEG abnormal group. Compared with the TEG normal group, the volume of blood loss, red blood cell count, and volume of plasma transfusion in the TEG abnormal group significantly increased within 24 hours after surgery. The results of the logistic regression analysis identified the use of clopidogrel, platelet count at T2, fibrinogen level at T2, and abnormality in TEG value as independent predictors for the significant increase in perioperative blood loss $(P<0.001)$.

Conclusion: The abnormality in TEG value after heparin neutralization is correlated with massive hemorrhage and blood transfusion during the perioperative period in OPCABG. TEG detection can assist in clinical treatment and reduce the volume of blood lost in a hemorrhage and the volume of blood required in a transfusion during OPCABG.

Keywords: thromboelastography, off-pump coronary artery bypass grafting, perioperative period, blood loss, blood transfusion

\section{Introduction}

In patients who need emergency off-pump coronary artery bypass grafting (OPCABG), dual antiplatelet therapy (DAPT) may significantly increase the risk of perioperative bleeding. ${ }^{1,2}$ Hemorrhage is therefore one of the main complications seriously affecting the clinical prognosis of patients undergoing OPCABG. ${ }^{3}$ However, the discontinuation of DAPT before the operation can increase the incidence of thromboembolism events, which presents a dilemma for both clinicians and patients. The traditional clinical response is to use freshly frozen plasma or platelets, but this approach is based only on the experience of traditional coagulation tests, which include prothrombin time (PT) and have a long testing period - they have limited predictive value in evaluating the function of coagulation 
and the volume of blood loss. ${ }^{4}$ Thus, more timely and effective detection methods are needed to provide a basis for clinical treatment.

In recent years, thromboelastography (TEG) has gained increasing recognition as a method of evaluating the function of blood coagulation. ${ }^{5}$ As a more accurate detection and evaluation method, TEG has a shorter detection duration than traditional laboratory tests ${ }^{5}$ and can provide continuous and quantitative information concerning the process from the formation of blood clots to the appearance of fibrinolysis. ${ }^{6-9}$

The present retrospective study aims to explore the correlation between abnormal TEG parameters and the increase in the incidence of perioperative hemorrhage in patients undergoing OPCABG. It also aims to identify the relationship between the changes in TEG parameters and the demand for blood transfusion in OPCABG.

\section{Methods}

\section{Subjects}

The data of 398 patients who underwent OPCABG procedures in our department between April 2016 and January 2019 were retrospectively analyzed. All patients had indications for surgery but had no contraindications. Patients without TEG detection, patients transferred to emergency external circulation, and patients complicated with other operations were excluded.

For all patients, blood drawn from the central venous catheter before anesthesia induction (T1) and 10 minutes after heparin neutralization (T2) was used for TEG detection. To confirm sufficient heparin neutralization, activated clotting time (ACT) was measured with a blood sample drawn at T2. The recorded TEG parameters included the $\mathrm{R}$ value, $\mathrm{K}$ value, $\alpha$ angle, and maximum amplitude. The patients were divided into two groups based on the detection results of TEG at T2: a TEG normal group and a TEG abnormal group. The TEG abnormal group included patients with at least one abnormal TEG parameter.

The study was approved by the Ethics Committee of Hebei Medical University (2020-R270), and all patients provided signed informed consent.

\section{Methods}

Aspirin was given prior to the operation and again six hours after the operation if the bleeding was in the normal range. Clopidogrel was administered one day before surgery. General anesthesia was performed for all patients, and $1.5 \mathrm{mg} / \mathrm{kg}$ of heparin was given before the left internal mammary artery was severed. The grafting was initiated when the detected ACT was $\geq 300$ seconds. Protamine sulfate $(0.8 \mathrm{mg} / 1 \mathrm{mg}$ of heparin) was given for neutralization with the completion of the grafting. During the operation, the hematocrit was maintained above $25 \%$ by the transfusion of red blood cells and the use of a blood recovery machine. In cases of continuous bleeding after sufficient surgical hemostasis and protamine neutralization (as confirmed by ACT), blood transfusion or cold precipitation was given under the joint agreement of the anesthesiologist and surgeon. The first operation was through the median sternal incision, while the second was along the original incision.

After surgery, the patients were sent back to the intensive care unit (ICU) in the cardiac surgery department and treated according to standardized postoperative treatment procedures. In cases of a hemorrhage of more than $200 \mathrm{~mL} / \mathrm{h}$ for up to two hours, blood plasma or platelets were infused. Where postoperative bleeding was more than $200 \mathrm{~mL} / \mathrm{h}$ for six hours or more than $400 \mathrm{~mL}$ in the first hour, a reoperation was performed. The final decision about a blood transfusion or reoperation was jointly made by the clinicians in the ICU and surgeons.

In this study, the patients' BMIs were $26.14 \pm 3.25$ (TEG normal group) and $28.98 \pm 2.84$ (TEG normal group). Considering that the blood volume in the human body is about $7-8 \%$ of body weight, $20 \%$ of the estimated blood volume was calculated to be $1000 \mathrm{~mL}$.

\section{Statistical Analysis}

SPSS 24.0 (IBM Corporation, Chicago, America) software was used for statistical analysis. Measurement data were expressed as $\bar{X} \pm S$, while enumeration data were expressed as percentages. For comparisons between groups of measurement data, a Student's $t$-test was used for normally distributed data and the Mann-Whitney $U$-test for non-normally distributed data. For comparisons between groups of enumeration data, normal distribution was tested using a $\chi^{2}$ test, and non-normal distribution was tested using the Kruskal-Wallis test. In the test for confounding factors, the single-factor logistic regression equation was used to analyze the influence of gender, diabetes mellitus, other baseline data, and perioperative risk factors on the incidence of serious hemorrhage events in patients undergoing OPCABG. All significant variables in the univariate analysis, as well as those previously considered to be predictors for the risk of hemorrhage, were included in 
the multivariate logistic regression equation in order to test the adjusted odds ratio (OR) and 95\% confidence interval. All statistical analyses were two-tailed tests, and $P<0.05$ was considered statistically significant.

\section{Results}

\section{Clinical Characteristics and Preoperative Baseline Data of Patients}

An evaluation of the clinical characteristics and preoperative baseline data of the 398 patients is given in Table 1 . The percentage of patients who received clopidogrel within three days before the operation was 53.43\% (TEG normal group) and $61.16 \%$ (TEG abnormal group) $(P=0.093)$, and the average number of coronary grafts was $3.31 \pm 0.76$ (TEG normal group) and $3.58 \pm 0.82$ (TEG abnormal group) ( $P=$ $0.429)$. There were no statistical differences in baseline data between the two groups $(P>0.05)$.

\section{Intraoperative Laboratory Tests and TEG Results in OPCABG}

The changes in laboratory tests and TEG parameters are shown in Table 2. Hemoglobin levels, platelet counts, and fibrinogen levels significantly decreased at T2 from their baseline values, while PT and activated partial thromboplastin time (APTT) significantly increased. Although the mean values of fibrinogen levels at T2 were within the reference range, they were lower than those at T1, and the difference was statistically significant $(P<0.05)$.

\section{Comparison of Intraoperative Conditions}

Whether TEG parameters were normal at T2, analysis of postoperative coagulation function and laboratory indicators, volume of perioperative blood loss, blood transfusion demand, and postoperative complications are shown in Tables 3 and 4. Blood transfusions were given to all patients according to their situation after sufficient heparin neutralization was confirmed by ACT.

For patients in the TEG abnormal group, the volume of blood loss, red blood cell count, volume of plasma transfusion, and frequency of hemostasis during the second thoracotomy significantly increased within 24 hours postoperation, and the difference was statistically significant when compared with patients in the TEG normal group. There were no significant differences in the duration of tracheal intubation, postoperative myocardial infarction

Table I Clinical Characteristics and Preoperative Baseline Data of Patients Between These Two Groups

\begin{tabular}{|c|c|c|c|}
\hline Projects & $\begin{array}{l}\text { TEG Normal } \\
\text { Group } n=277\end{array}$ & $\begin{array}{l}\text { TEG Abnormal } \\
\text { Group } n=|2|\end{array}$ & $P$ value \\
\hline Age (years) & $67.29 \pm 10.52$ & $68.54 \pm 8.90$ & 0.173 \\
\hline Male & $157(56.68 \%)$ & $60(49.58 \%)$ & 0.196 \\
\hline Body mass index $\left(\mathrm{kg} / \mathrm{m}^{2}\right)$ & $26.14 \pm 3.25$ & $28.98 \pm 2.84$ & 0.227 \\
\hline EuroSCORE & $4.19 \pm 2.50$ & $4.33 \pm 2.7 \mathrm{I}$ & 0.551 \\
\hline Hypertension & $216(77.98 \%)$ & $96(79.34 \%)$ & 0.828 \\
\hline Diabetes mellitus & $90(32.49 \%)$ & $36(29.75 \%)$ & 0.696 \\
\hline Old cerebral infarction (>30 days) & $44(15.88 \%)$ & $12(9.92 \%)$ & 0.317 \\
\hline Carotid disease & $23(8.30 \%)$ & $13(10.74 \%)$ & 0.773 \\
\hline Chronic obstructive Pulmonary disease & $39(14.08 \%)$ & $23(19.01 \%)$ & 0.364 \\
\hline Congestive heart failure & $33(11.91 \%)$ & $13(10.74 \%)$ & 0.891 \\
\hline Unstable angina pectoris & $133(48.01 \%)$ & $62(51.23 \%)$ & 0.575 \\
\hline NSTEMI & $53(19.13 \%)$ & $24(19.83 \%)$ & 0.934 \\
\hline Left main coronary artery & $75(27.07 \%)$ & $28(23.14 \%)$ & 0.402 \\
\hline Past history of $\mathrm{PCl}$ & $19(6.86 \%)$ & $7(5.78 \%)$ & 0.882 \\
\hline Left ventricular ejection Fraction (\%) & $49.31 \pm 12.88$ & $48.17 \pm 13.35$ & 0.082 \\
\hline Continous administration of clopidogrel within three days before the operation & I48(53.43\%) & $74(61.16 \%)$ & 0.093 \\
\hline Hemoglobin level(g/dL) & $13.55 \pm 1.67$ & $11.08 \pm 1.29$ & 0.161 \\
\hline Platelet count $\left(* 10^{9} / \mathrm{L}\right)$ & $247.33 \pm 37.56$ & $209.06 \pm 22.57$ & 0.186 \\
\hline Fibrinogen level(g/L) & $3.82 \pm 0.96$ & $3.19 \pm 1.33$ & 0.073 \\
\hline Prothrombin time(PT) (s) & $11.37 \pm 0.28$ & $9.89 \pm 1.51$ & 0.627 \\
\hline Activated partial thromboplastin time (APTT) (s) & $32.6 I \pm 4.29$ & $30.26 \pm 6.07$ & 0.576 \\
\hline Creatinine $(\mu \mathrm{mol} / \mathrm{L})$ & $82.57 \pm 19.16$ & $79.04 \pm 16.23$ & 0.249 \\
\hline
\end{tabular}

Abbreviations: TEG, thromboelastography; NSTEMI, non-ST segment elevation myocardial infarction; PCl, percutaneous transluminal coronary intervention; APTT, activated partial thromboplastin time; PT, prothrombin time. 
Table 2 The Changes in Intraoperative Laboratory Tests and TEG Parameters in OPCABG

\begin{tabular}{|l|c|c|c|}
\hline Laboratory Tests & TI & T2 & $P$ \\
\hline Hemoglobin level(g/dL) & $13.27 \pm 1.25$ & $10.72 \pm 1.54$ & $<0.001$ \\
\hline Platelet count $\left(* 10^{9} / \mathrm{L}\right)$ & $235.08 \pm 31.46$ & $183.77 \pm 29.52$ & $<0.001$ \\
\hline Fibrinogen level(g/dL) & $3.65 \pm 1.27$ & $2.69 \pm 1.92$ & 0.027 \\
\hline PT(s) & $10.83 \pm 1.36$ & $14.97 \pm 1.59$ & 0.007 \\
\hline APTT(s) & $31.52 \pm 6.71$ & $35.93 \pm 8.22$ & 0.004 \\
\hline TEG tests & & & \\
R-time(min) & $6.38 \pm 1.74$ & $2.59 \pm 1.46$ & $<0.001$ \\
$\alpha$-angle $\left({ }^{\circ}\right)$ & $65.64 \pm 5.50$ & $71.67 \pm 4.82$ & $<0.001$ \\
K(min) & $1.97 \pm 0.48$ & $1.33 \pm 0.41$ & $<0.001$ \\
MA(mm) & $63.21 \pm 7.36$ & $66.74 \pm 5.69$ & $<0.001$ \\
\hline
\end{tabular}

Abbreviations: TEG, thromboelastography; NSTEMI, non-ST segment elevation myocardial infarction; PCl, percutaneous transluminal coronary intervention; APTT, activated partial thromboplastin time; PT, prothrombin time.

(according to the criteria of postoperative cardiac infarction in coronary artery bypass grafting), postoperative ventricular fibrillation, bedside dialysis, and in-hospital mortality between the two groups (see Table 4).

\section{Logistic Regression Analysis of Factors Correlated with Blood Loss and Blood Transfusion}

After comparing the data of patients with obvious hemorrhage during the perioperative period and those without, single-factor logistic regression analysis was used to include all variables with $P<0.2$ into the single-factor analysis. The statistical results of the prediction factors for significant hemorrhage during the perioperative period are shown in Table 5. Based on the results of the single-factor analysis and clinical conditions, the indexes of diabetes mellitus, continuous administration of clopidogrel three days before surgery, fibrinogen levels at T2, and abnormal TEG parameters were included in the multivariate logistic regression analysis. The results (see Table 6) demonstrate that the continuous administration of clopidogrel three days before surgery, fibrinogen levels at T2, and abnormal TEG parameters are independent risk factors for the significantly increased risk of perioperative hemorrhage.

\section{Discussion}

It takes a long time to perform traditional laboratory tests, and they reflect the state of blood coagulation in a relatively one-sided way. Clinical blood-transfusion therapy based on this method, therefore, cannot be carried out in a timely manner, resulting in insufficient blood transfusions that lead to continuous hemorrhage or to excessive blood transfusions that lead to excessive production of harmful thrombin and arterial or venous embolism. ${ }^{10}$ Therefore, TEG, as a more accurate detection and evaluation method, has recently attracted the attention of clinicians. The present study investigated the factors that influence significant perioperative hemorrhage and

Table 3 Intraoperative Condition, Laboratory Tests and TEG at T2

\begin{tabular}{|c|c|c|c|}
\hline & $\begin{array}{l}\text { TEG Normal } \\
\text { Group } n=277\end{array}$ & $\begin{array}{c}\text { TEG Abnormal } \\
\text { Group } n=|2|\end{array}$ & $P$ value \\
\hline Number of bridging Vessels & $3.31 \pm 0.76$ & $3.58 \pm 0.82$ & 0.429 \\
\hline Duration of the operation(min) & $238.53 \pm 48.17$ & $249.20 \pm 54.18$ & 0.083 \\
\hline The left internal mammary artery & $274(98.92 \%)$ & $120(99.17 \%)$ & 0.998 \\
\hline \multicolumn{4}{|l|}{ During the operation at $\mathrm{T} 2$} \\
\hline Hemoglobin level (g/dL) & $10.28 \pm 1.53$ & $9.81 \pm 2.23$ & 0.196 \\
\hline Platelet count $\left(* 10^{9} / \mathrm{L}\right)$ & $196.80 \pm 29.74$ & $163.81 \pm 11.86$ & 0.076 \\
\hline Fibrinogen level(g/L) & $3.12 \pm 0.96$ & $2.46 \pm 1.33$ & 0.073 \\
\hline $\mathrm{PT}(\mathrm{s})$ & $|2.66 \pm| .3 \mid$ & $14.93 \pm 2.47$ & 0.136 \\
\hline APTT(s) & $34.87 \pm 6.91$ & $35.62 \pm 9.29$ & 0.681 \\
\hline \multicolumn{4}{|l|}{ TEG tests } \\
\hline R-time(min) & $2.71 \pm 1.62$ & $2.36 \pm 1.22$ & $<0.001$ \\
\hline$\alpha$-angle $\left({ }^{\circ}\right)$ & $73.52 \pm 3.96$ & $70.96 \pm 2.88$ & $<0.001$ \\
\hline $\mathrm{K}(\min )$ & $1.13 \pm 0.28$ & $1.42 \pm 0.53$ & $<0.001$ \\
\hline $\mathrm{MA}(\mathrm{mm})$ & $69.27 \pm 4.86$ & $61.13 \pm 6.88$ & $<0.001$ \\
\hline
\end{tabular}

Abbreviations: TEG, thromboelastography; NSTEMI, non-ST segment elevation myocardial infarction; PCI, percutaneous transluminal coronary intervention; APTT, activated partial thromboplastin time; PT, prothrombin time. 
Table 4 Postoperative Blood Loss, Blood Transfusion and Complications Between the Two Groups

\begin{tabular}{|c|c|c|c|}
\hline & $\begin{array}{l}\text { TEG Normal Group } \\
\qquad n=277\end{array}$ & $\begin{array}{l}\text { TEG Abnormal Group } \\
\qquad n=|2|\end{array}$ & $P$ value \\
\hline The volume of postoperative drainage within 24 hours $(\mathrm{mL})$ & $496.60 \pm 222.17$ & $613.56 \pm 198.43$ & 0.008 \\
\hline The postoperative transfusion volume of RBC(units) & $1.63 \pm 1.44$ & $2.70 \pm 1.69$ & $<0.001$ \\
\hline The postoperative transfusion volume of $\mathrm{FFP}(\mathrm{mL})$ & $396.52 \pm 68.27$ & $528.37 \pm 119.96$ & $<0.001$ \\
\hline The postoperative transfusion volume of platelet(units) & 0.00 & 0.00 & - \\
\hline The second thoracotomy & $2(0.72 \%)$ & $3(2.48 \%)$ & $<0.001$ \\
\hline The duration of tracheal intubation(min) & $266.32 \pm 47.73$ & $319.67 \pm 61.28$ & 0.075 \\
\hline $\begin{array}{l}\text { Postoperative myocardial infarction(the criteria of postoperative cardiac } \\
\text { infarction) }\end{array}$ & $12(4.69 \%)$ & $5(4.13 \%)$ & 0.989 \\
\hline Postoperative ventricular fibrillation & 0.00 & 0.00 & - \\
\hline Acute renal injury & $42(15.16 \%)$ & $20(16.52 \%)$ & 0.801 \\
\hline Bedside dialysis & 0.00 & 0.00 & - \\
\hline Length of stay in the ICU(day) & $2.43 \pm 0.71$ & $3.67 \pm 1.29$ & 0.079 \\
\hline Hospital length of stay(day) & $7.28 \pm 1.22$ & $7.33 \pm 1.51$ & 0.856 \\
\hline In-hospital mortality & $2(0.72 \%)$ & $\mathrm{I}(0.83 \%)$ & 0.643 \\
\hline
\end{tabular}

Note: CABG related myocardial infarction: patients with cardiac troponin elevation more than 10 times the upper 99 th percentile of the reference value after CABG. Abbreviations: TEG, thromboelastography; NSTEMI, non-ST segment elevation myocardial infarction; PCI, percutaneous transluminal coronary intervention; APTT, activated partial thromboplastin time; PT, prothrombin time.

transfusion demand in patients undergoing OPCABG, particularly focusing on the predictive value of TEG parameters for significant perioperative hemorrhage.

Based on the TEG parameters after heparin neutralization, the present study found that patients were in a state of hypercoagulation in terms of coagulation factors, fibrinogen levels, and hyperactive platelet function after OPCABG compared with the baseline data before surgery; this finding is consistent with previous studies. ${ }^{11,12}$ However, the results of laboratory tests revealed that fibrinogen levels decreased with the prolongation of PT and APTT. Although the laboratory test results were not consistent with the results of the TEG, the differences are supported by previous research, ${ }^{12}$ which suggests that they might be caused by three factors. First, TEG detection is based on testing whole-blood components, while PT and APTT are based on testing plasma alone, so they do not take into account the influence of red blood cells and platelets on coagulation, resulting in the incomprehensive evaluation of coagulation function. ${ }^{13}$ Second, TEG detection reflects coagulation function, while laboratory tests reflect the quantity of the blood components. Last, hemodilution during surgery may be a contributing factor.
The differences in the level of coagulation factors, fibrinogen function, and platelet function between the two groups at T2 were statistically significant, and coagulation dysfunction was more obvious in the TEG abnormal group. Multivariate logistic regression analysis revealed that the administration of clopidogrel within three days before surgery, platelet count, fibrinogen levels, and TEG parameters at $\mathrm{T} 2$ were significantly correlated with the increased risk of perioperative hemorrhage, while PT and APTT could not predict the increase in perioperative hemorrhage and blood transfusion. This finding is consistent with previous studies. ${ }^{14}$

In terms of the recent postoperative indicators in patients, such as the volume of drainage within 24 hours, red blood cell count, and volume of plasma transfusion, combined with hemostasis during the second thoracotomy, the differences between the TEG abnormal group and TEG normal group in the present study were statistically significant. It was found that the abnormality in TEG parameters could increase the risk of perioperative hemorrhage by 2.9 times. Hemorrhage after cardiac surgery is correlated with many factors, including patient characteristics, preoperative medication, operation conditions, and anesthesia management. Previous studies ${ }^{15-17}$ have shown 
Table 5 Logistic Regression Analysis of the Single Factor Correlated to Blood Loss and Blood Transfusion

\begin{tabular}{|c|c|c|c|c|c|}
\hline The Single Factor & $\begin{array}{c}\text { } \beta \text { (Partial } \\
\text { Regression } \\
\text { Coefficient) }\end{array}$ & SE & $\begin{array}{c}\text { Wald } \chi^{2} \\
\text { Value }\end{array}$ & $P$ value & OR(95\% Cl) \\
\hline Male & 0.097 & 0.070 & 1.788 & 0.179 & $1.101(0.956,1.277)$ \\
\hline Diabetes mellitus & -0.172 & 0.075 & 6.898 & 0.012 & $0.852(0.763,0.961)$ \\
\hline Hypertension & 0.186 & 0.098 & 4.992 & 0.067 & $1.236(1.001,1.403)$ \\
\hline Unstable angina pectoris & 0.039 & 0.088 & 0.199 & 0.676 & $1.042(0.898,1.236)$ \\
\hline NSTEMI & 0.375 & 0.402 & 0.917 & 0.364 & $1.476(0.683,3.149)$ \\
\hline $\begin{array}{l}\text { Continous administration of } \\
\text { clopidogrel within three days before } \\
\text { the operation }\end{array}$ & 0.288 & 0.076 & 12.526 & $<0.001$ & $1.488(1.243,1.637)$ \\
\hline \multicolumn{6}{|l|}{ Before the operation at $\mathrm{TI}$} \\
\hline Hemoglobin level(g/dL) & -0.049 & 0.073 & 0.306 & 0.588 & $0.967(0.832,1.125)$ \\
\hline Platelet count $\left(* 10^{9} / \mathrm{L}\right)$ & -0.066 & 0.079 & 0.698 & 0.414 & $0.959(0.815,1.092)$ \\
\hline Fibrinogen level(g/L) & -0.267 & 0.515 & 0.253 & 0.677 & $1.298(0.976,2.448)$ \\
\hline PT & 0.013 & 0.041 & 0.058 & 0.768 & $1.002(0.952,1.037)$ \\
\hline APTT & 0.042 & 0.097 & 3.926 & 0.063 & I. $188(0.998,1.253)$ \\
\hline \multicolumn{6}{|l|}{ During the operation at $\mathrm{T} 2$} \\
\hline Hemoglobin level(g/dL) & -0.896 & 0.567 & 5.338 & 0.003 & $0.83 \mathrm{I}(0.796,0.952)$ \\
\hline Platelet count $\left(* 10^{9} / \mathrm{L}\right)$ & -0.237 & 0.029 & 42.610 & $<0.001$ & $0.873(0.725,1.089)$ \\
\hline $\mathrm{PT}(\mathrm{s})$ & 0.166 & 0.871 & 0.795 & 0.382 & $1.179(0.829,1.679)$ \\
\hline APTT(s) & 0.121 & 0.217 & 0.256 & 0.638 & I.II6(0.737,1.758) \\
\hline Fibrinogen level(g/L) & -0.223 & 0.030 & 50.116 & $<0.001$ & $0.816(0.759,0.861)$ \\
\hline Abnormal TEG test results & 1.031 & 0.329 & 9.898 & $<0.001$ & $2.926(1.899,4.347)$ \\
\hline
\end{tabular}

Abbreviations: TEG, thromboelastography; NSTEMI, non-ST segment elevation myocardial infarction; PCl, percutaneous transluminal coronary intervention; APTT, activated partial thromboplastin time; PT, prothrombin time.

Table 6 Logistic Regression Analysis of Factors Correlated to Blood Loss and Blood Transfusion

\begin{tabular}{|c|c|c|c|c|c|}
\hline The Single Factor & $\begin{array}{c}\boldsymbol{\beta}(\text { Partial } \\
\text { Regression } \\
\text { Coefficient) }\end{array}$ & SE & $\begin{array}{c}\text { Wald } \chi^{2} \\
\text { Value }\end{array}$ & $P$ value & OR(95\% Cl) \\
\hline Diabetes mellitus & -0.385 & 0.124 & 3.278 & 0.196 & $0.867(0.778,1.007)$ \\
\hline $\begin{array}{l}\text { Continous administration of clopidogrel within } \\
\text { three days before the operation }\end{array}$ & 0.293 & 0.085 & 11.896 & $<0.001$ & $1.462(1.237,1.612)$ \\
\hline \multicolumn{6}{|l|}{ During the operation at $\mathrm{T} 2$} \\
\hline Hemoglobin level(g/dL) & -0.387 & 0.402 & 0.898 & 0.326 & $\mathrm{I} .453(0.762,2.237)$ \\
\hline Platelet count $\left(* 10^{9} / \mathrm{L}\right)$ & -0.228 & 0.027 & 40.782 & $<0.001$ & $0.889(0.762,1.127)$ \\
\hline Fibrinogen level(g/L) & -0.219 & 0.029 & 52.327 & $<0.001$ & $0.825(0.796,0.859)$ \\
\hline Abnormal TEG parameters & 1.036 & 0.331 & 9.899 & $<0.001$ & $2.928(1.898,4.349)$ \\
\hline
\end{tabular}

Abbreviations: TEG, thromboelastography; NSTEMI, non-ST segment elevation myocardial infarction; PCl, percutaneous transluminal coronary intervention; APTT, activated partial thromboplastin time; PT, prothrombin time.

that TEG can be used to preoperatively evaluate the platelet function in patients undergoing OPCABG, help surgeons choose the most suitable operation time, and reduce the waiting time before surgery. As mentioned in the 2017 European
Association for Cardio-Thoracic Surgery's Guidelines on Patient Blood Management for Adult Cardiac Surgery,${ }^{14}$ platelet function testing can be used to guide and determine the timing of cardiac surgery in patients who have recently 
received $\mathrm{P}_{2} \mathrm{Y}_{12}$ inhibitors or are receiving DAPT. The results of the present study identified a positive correlation between abnormal TEG parameters after heparin neutralization and the significant increase in perioperative hemorrhage during OPCABG. Through the evaluation of TEG in clinical practice, the coagulation function of patients after surgery can be observed, clinical transfusion strategies can be guided in a timely manner, and perioperative blood loss can be reduced.

The present study had some limitations. First, it was a single-center retrospective study. Second, statistics were not created for the results of the TEG, PT, APTT, and other data after 24 hours. Where patients had no obvious contraindications, they started antiplatelet therapy again six hours after OPCABG, which could have interfered with the coagulation function and test results. Third, some patients in the present study had acute coronary syndrome (ACS), and some continued to take clopidogrel within three days before the operation. Previous studies have shown that this can lead to an increased incidence of postoperative hemorrhage, ${ }^{18-20}$ in the present study, $53.43 \%$ (TEG normal group) and $61.16 \%$ (TEG abnormal group) of patients took clopidogrel within three days before surgery, but there was no significant difference between the two groups. Fourth, DAPT was investigated only in light of its association with aspirin and clopidogrel, although the current guidelines for the treatment of ACS also recommend the use of prasugrel and ticagrelor based on the ischemic vs hemorrhagic risk of the patient. In the TRITON-TIMI 38 and PLATO trials, in which prasugrel and ticagrelor, respectively, were tested against clopidogrel in combination with acetylsalicylic acid (ASA), both newer $\mathrm{P}_{2} \mathrm{Y}_{12}$ inhibitors were more effective than clopidogrel in preventing fatal outcomes, with a higher risk of bleeding in the TRITONTIMI 38 trial but not in the PLATO trial. Fifth, the present study did not define the hemoglobin threshold for transfusion and considered only platelet count rather than platelet function. Sixth, it is unclear whether the patients who had clopidogrel within three days before surgery were treated with DAPT or clopidogrel only. Seventh, the study did not clarify the extra precautions that should be taken in patients with abnormal TEG parameters during the postoperative period. The study did not clarify the TEG evaluation in the preoperative period, and what can TEG abnormal during T2 period add extra to avoid excessive bleeding. Last, the study did not identify which of the four TEG parameters was most valuable in predicting postoperative blood loss, bearing in mind that some parameters are interlinked.

\section{Conclusion}

The present study confirmed the role of abnormal TEG parameters in predicting significant perioperative blood loss and blood transfusion demand after heparin neutralization in patients undergoing OPCABG. It also provided support for its potential role in guiding blood-transfusion management in patients with non-surgical bleeding after OPCABG. Further prospective trials exploring the role of TEG during the perioperative period in OPCABG would be worthwhile.

\section{Ethics Approval and Consent to Participate}

I confirm that I have read the Editorial Policy pages. This study was conducted with approval from the Ethics Committee of Second Hospital of Hebei Medical University (2020-R270). This study was conducted in accordance with the declaration of Helsinki. Written informed consent was obtained from all participants.

\section{Acknowledgments}

We would like to acknowledge the hard and dedicated work of all the staff that implemented the intervention and evaluation components of the study.

\section{Funding}

Hebei Province 2016 Key Topics of Medical Science Research (20160105)- Clinical Application of thrombosis attempts in critical coronary bypass transplantation perforation.

\section{Disclosure}

The authors declare that they have no competing interests.

\section{References}

1. Roffi M, Gencer B, Storey RF, Andreotti F, Patrono C. Clinical perspectives and pearls from the 2015 ESC NSTE-ACS Guidelines. Curr Cardiol Rep. 2016;18(5):48. doi:10.1007/s11886-016-0722-0

2. Barbieri L, Pergolini P, Verdoia M, et al. Novara Atherosclerosis Study Group (NAS). Platelet reactivity in patients with impaired renal function receiving dual antiplatelet therapy with clopidogrel or ticagrelor. Vascul Pharmacol. 2016;79:11-15. doi:10.1016/j.vph.2015.10.006

3. Stone GW, Clayton TC, Mehran R, et al. Impact of major bleeding and blood transfusions after cardiac surgery: analysis from the Acute Catheterization and Urgent Intervention Triage strategY (ACUITY) trial. Am Heart J. 2012;163(3):522-529. doi:10.1016/j.ahj.2011.11.016

4. Kozek-Langenecker SA, Ahmed AB, Afshari A, et al. Management of severe perioperative bleeding: guidelines from the European Society of Anaesthesiology: first update 2016. Eur J Anaesthesiol. 2017;34 (6):332-395. 
5. Gorlinger K, Dirkmann D, Solomon C, Hanke AA. Fast interpretation of thromboelastometry in non-cardiac surgery: reliability in patients with hypo-, normo-, and hypercoagulability. $\mathrm{Br} J$ Anaesth. 2013;110(2):222-230. doi:10.1093/bja/aes374

6. Ak K, Isbir CS, Tetik S, et al. Thromboelastography-based transfusion algorithm reduces blood product use after elective CABG: a prospective randomized study. J Card Surg. 2009;24(4):404-410. doi:10.1111/j.1540-8191.2009.00840.x

7. Mace H, Lightfoot N, McCluskey S, et al. Validity of thromboelastometry for rapid assessment of fibrinogen levels in heparinized samples during cardiac surgery: a Retrospective, Single-center, Observational Study. J Cardiothorac Vasc Anesth. 2016;30 (1):90-95. doi:10.1053/j.jvca.2015.04.030

8. Pagano D, Milojevic M, Meesters MI, et al. 2017 EACTS/EACTA Guidelines on patient blood management for adult cardiac surgery. Eur J Cardiothorac Surg. 2018;53(1):79-111.

9. Nakayama Y, Nakajima Y, Tanaka KA, et al. Thromboelastometryguided intraoperative haemostatic management reduces bleeding and red cell transfusion after paediatric cardiac surgery. Br J Anaesth. 2015;114(1):91-102. doi:10.1093/bja/aeu339

10. Schöchl H, Voelckel W, Maegele M, Kirchmair L, Schlimp CJ. Endogenous thrombin potential following hemostatic therapy with 4-factor prothrombin complex concentrate: a 7-day observational study of trauma patients. Crit Care. 2014;18(4):R147. doi:10.1186/ cc13982

11. Singh SK, Devenraj V, Tewarson V, Kumar S, Kaushal D, Chandra T. Thromboelastography in off-pump coronary artery bypass grafting. Asian Cardiovasc Thorac Ann. 2015;23(4):430-434. doi:10.1177/ 0218492314558636

12. Rafiq S, Johansson PI, Kofoed KF, et al. Thrombelastographic hypercoagulability and antiplatelet therapy after coronary artery bypass surgery (TEG-CABG trial): a randomized controlled trial. Platelets. 2017;28(8):786-793. doi:10.1080/09537104.2017.1280147

13. Pillai RC, Fraser JF, Ziegenfuss M, Bhaskar B. The influence of circulating levels of fibrinogen and perioperative coagulation parameters on predicting postoperative blood loss in cardiac surgery: a Prospective Observational Study. J Card Surg. 2014;29 (2):189-195. doi:10.1111/jocs.12255
14. Boer C, Meesters MI, Milojevic M. Task force on patient blood management for adult cardiac surgery of the European Association for Cardio-Thoracic Surgery (EACTS) and the European Association of Cardiothoracic Anaesthesiology (EACTA). 2017 EACTS/EACTA Guidelines on patient blood management for adult cardiac surgery. J Cardiothorac Vasc Anesth. 2018;32(1):88-120. doi:10.1053/j. jvca.2017.06.026

15. Yang Z, Xie Z, Pei X, Quan X, Feng D. Effect of thrombelastography on timing of coronary artery bypass grafting. Exp Ther Med. 2018;16 (2):579-584. doi:10.3892/etm.2018.6202

16. van Diepen S, Fuster V, Verma S, et al. Dual antiplatelet therapy versus aspirin monotherapy in diabetics with multivessel disease undergoing CABG: FREEDOM Insights. $J$ Am Coll Cardiol. 2017;69(2):119-127. doi:10.1016/j.jacc.2016.10.043

17. Levine GN, Bates ER, Bittl JA, et al. 2016 ACC/AHA guideline focused update on duration of dual antiplatelet therapy in patients with coronary artery disease: a report of the American College of Cardiology/American Heart Association Task Force on Clinical Practice Guidelines. $J$ Thorac Cardiovasc Surg. 2016;152 (5):1243-1275. doi:10.1016/j.jtcvs.2016.07.044

18. Valgimigli M, Bueno H, Byrne RA; ESC Scientific Document Group; ESC Committee for Practice Guidelines (CPG); ESC National Cardiac Societies. 2017 ESC focused update on dual antiplatelet therapy in coronary artery disease developed in collaboration with EACTS: the Task Force for dual antiplatelet therapy in coronary artery disease of the European Society of Cardiology (ESC) and of the European Association for Cardio-Thoracic Surgery (EACTS). Eur Heart J. 2018;39(3):213-260. doi:10.1093/eurheartj/ehx419

19. Levi M, Levy JH, Andersen HF, Truloff D. Safety of recombinant activated factor VII in randomized clinical trials. $N$ Engl J Med. 2010;363(19):1791-1800. doi:10.1056/NEJMoa1006221

20. Weber CF, Görlinger K, Meininger D, et al. Point-of-care testing: a prospective, randomized clinical trial of efficacy in coagulopathic cardiac surgery patients. Anesthesiology. 2012;117(3):531-547. doi:10.1097/ALN.0b013e318264c644
International Journal of General Medicine

\section{Publish your work in this journal}

The International Journal of General Medicine is an international, peer-reviewed open-access journal that focuses on general and internal medicine, pathogenesis, epidemiology, diagnosis, monitoring and treatment protocols. The journal is characterized by the rapid reporting of reviews, original research and clinical studies across all disease areas. The manuscript management system is completely online and includes a very quick and fair peer-review system, which is all easy to use. Visit http://www.dovepress.com/ testimonials.php to read real quotes from published authors. 